\title{
Should the South African red meat classification system be revised or maintained? A review
}

\author{
Z. Soji. \& V. Muchenje \\ Department of Livestock and Pasture Science, Faculty of Science and Agriculture, University of Fort Hare, \\ Private Bag X1314, Alice, 5700, South Africa
}

(Received 27 December 2016; Accepted 17 June 2017; First published online 24 July 2017)

\begin{abstract}
Copyright resides with the authors in terms of the Creative Commons Attribution 4.0 South African License.
See: http://creativecommons.org/licenses/by/4.0/za

Condition of use: The user may copy, distribute, transmit and adapt the work, but must recognize the authors and the South African Journal of Animal Science.
\end{abstract}

\begin{abstract}
The objective of this review was to determine whether the current South African red meat classification system still needs to be revised and changed or maintained. It also gives insight into the most significant challenges related to meat quality evaluation in this system. Red Meat Research and Development South Africa (RMRD SA) was requested to lead an investigation into the relevance of the current South African red meat classification system. A final decision was made to maintain the system as it was in 2016. Nonetheless, it is still unclear whether consumers buy meat according to the standards set by the system, since it is mostly understood and practised efficiently by middlemen, especially abattoir operators. The general perception that this system is not quality based, but descriptive, has resulted in seeming non-transparency among some red meat industry stakeholders. Although the red meat industry is emphasizing that a quality assurance system remains too expensive to be implemented in South Africa and that the current system should be sustained, there is still room for revising it. All predictions in this review indicate that the present system cannot satisfy all the needs of the current consumer. The system seems to be inclined towards meat traders, since it is value based and may not reflect the expectations and needs of consumers in terms of meat quality. This paper therefore concluded that the South African red meat classification system still needs to be revised and more research should be done for it to become more effective.
\end{abstract}

Keywords: Assurance system, consumer needs, meat quality, meat traders, red meat industry

\# Corresponding author: vmuchenje@ufh.ac.za

\section{Introduction}

The development of the South African red meat classification system can be traced back to 1936 . Initially, it was referred to as a grading system, in which animal age was used as the first characteristic to rank carcasses. Later, in 1992, the South African meat industry was deregulated (National Agricultural Marketing Council (NAMC), 2001). This led to the development of the current South African red meat classification system to replace the grading system, which was believed to be biased, since it ranked carcasses in order of merit, from the most preferred to the least (KwaZulu-Natal Department of Agriculture and Environmental Affairs (KZN DAEA), 2005). The current system was therefore developed to provide a basis for meat traders to describe carcasses in simple terms for pricing and purchasing (South African Meat Industry Company (SAMIC), 2006). Since the discovery of constraints in meat quality evaluation in the current system, plans to improve it have been developed by researchers in consultation with the meat industry. However, industry stakeholders are presently still indecisive as to whether the current system is satisfactory to describe the quality of red meat, in particular meat eating-quality attributes such as tenderness.

Thus, in an attempt to revise the current system, a task team under the auspices of RMRD SA, consisting of scientists from various research organisations, was established in 2009 (RMIF, 2016). This was followed by a review by Strydom (2011), which focused on quality-related principles of the South African beef classification system in relation to world grading and classification systems. The review concluded that the standards used in the current South African classification system do not adequately define the quality for different meat classes. Research concerning the South African classification system has therefore been conducted since then. As a result, at the 12th Meat Symposium, which was conducted by RMRD SA in 2014, a call for research on the relevance of system was proposed. Thereafter, a special issue on this was published in the South African Journal of Animal Science in 2015. The findings were presented and 
discussed at the RMRD SA carcass classification workshop in 2016. The Red Meat Industry Forum (RMIF) (2016) highlighted that the papers and research that were conducted on this issue were of very high quality, but did not prove conclusively that a change to the current classification system is necessary. This was related to a range of factors, which include production systems, breed, and the use of growth promoters, which are not included in the South African system.

The current system classifies meat based on five characteristics (age, fat, conformation, bruise/damage, and sex), but to a large extent slaughter age and the amount of subcutaneous fat form the basis of pricing for classified carcasses. Although a carcass trait such as bruising forms part of the classification system, it is unable to quantify the effects of bruising on meat quality attributes. The consequences of bruised carcasses can be seen on attributes such as dark coloured meat (DFD), toughness, reduction of meat shelf life, poor palatability, and reduced water-holding capacity (Muchenje et al., 2009; Vimiso \& Muchenje, 2013). Although it may seem impossible to quantify the effect of bruising based on these parameters, certain abattoir management techniques to reduce the adverse effects of bruising on such meat quality parameters could be introduced to the current system. Such techniques include the time at which trimming of bruised carcasses is done at the abattoir (discussed below). Information about the effect of bruising on meat quality of different carcass classes is critical to the meat industry and consumers. Beef meat quality, in particular, is a highly inconstant factor, which depends on preand post-slaughter treatments (Guzek et al., 2016), including predisposing factors to bruising. The value of the carcass should therefore be based on yield and quality (Bonny et al., 2016) rather than a mere description of its features. It is therefore important to quantify the relationship between bruising and meat quality in the red meat classes.

Additionally, the significance of the conformation class to beef or mutton carcasses is still unclear. Some researchers postulate that conformation is meaningful only for consumer cut preferences, whether in beef or mutton carcasses, and is thus less important, because it is not related to meat quality (SAMIC, 2006; Hope-Jones, 2010; Strydom, 2011). On the other hand, some researchers argue that conformation is more important for beef carcasses than for sheep carcasses, since sheep carcasses have less variability in conformation (RMIF, 2016). This has led to controversy in the meat industry about whether to eliminate the conformation class on sheep carcasses, perhaps to develop a separate system for sheep carcasses or to eliminate conformation classes on both cattle and sheep. The main problem that could have resulted in this controversy is the unclear link between conformation and meat quality of both mutton and beef carcasses. Consequently this calls for further research.

Another interesting debate that arose at the carcass classification workshop, which showcased the need for re-evaluation of the current classification system, was whether $A$ and $A B$ carcasses should be combined. There are several references to reasons that these classes were not combined, including research conducted by the SAMIC in the mid-1990s, which indicated that meat tenderness decreases with age. Consequently, Government Notice R.342.1999 was released, which stated that meat from animals with no permanent incisors (A class) was more tender than that of animals with up to two permanent incisors ( $A B$ class). Some researchers think that because of production technologies, effectiveness in achieving production goals and limitations in the current system to distinguishing between small differences in carcass characteristics, these classes might not currently have much variation. Thus, more research needs to be conducted to prove this.

Likewise, the controversy around meat in diets, in which the World Health Organisation (WHO) (2016) reported that the consumption of high levels of unprocessed mammalian muscle meat from beef, veal, pork, lamb, mutton and chevon might be carcinogenic to humans, signals the need for a more effective classification system. Although it is still debatable, the WHO report indicated that besides increased risks of cancer, high intake of red meat can heighten the risk of other life-threatening diseases, which include coronary heart disease, stroke, and Type II diabetes. Thus a quality-based classification system could help in determining and tracing the red meat classes and quantities that might predispose consumers to dietary diseases that are perceived to be linked to red meat consumption. In the light of these issues, it is of paramount importance to consider more research on the red meat classification system. Questions about whether the current system should be maintained as is, amended or changed completely need to be answered. This paper does not seek to investigate or provide a discussion of all classification systems used globally or their development history as discussed by Polkinghorne \& Thompson (2008). Neither does it seek to give a detailed review on the South African classification system, which Strydom (2011) did in detail. The concept that is advanced revolves around the current dynamics in revising the classification system in relation to its implications on the meat quality-related preferences of the current consumer. The review highlights attempts that have been made to refine current South African classification with an objective to give insights into whether it needs to be revised and changed. 


\section{Industry views on the current classification system}

In a communique that was released on behalf of RMRD SA by the RMIF (2016), the most significant changes that have occurred since the implementation of the current system were highlighted:

- There is an increase in beef carcass mass from $210 \mathrm{~kg}$ (1993) to $266 \mathrm{~kg}(2013)$.

- The use of growth promoters in both extensive and intensive production systems has increased.

- The fat content of carcasses has reduced significantly compared with historical values.

- The methods in which the product is processed at abattoirs and retailers have also changed.

Because of these changes in South African red meat, one could argue that the problem with the current classification system is that animals from different production systems in each carcass class may produce a completely different product. Furthermore, recent research has suggested that variation within carcass classes has increased substantially owing to differences between livestock breeds, production systems and the use of modern feedstuffs and growth-enhancing technologies (Webb, 2015). None of these factors, however, are considered in the current system. The South African red meat industry argues that amending the current meat classification system would not address these issues (RMIF SA, 2016). Thus the red meat industry has agreed that the current system is still relevant, but the question that is left unanswered is whether the system is appropriate to producers and retailers or to consumers.

\section{Challenges besetting consumers in the current classification system}

Finding a classification system that would be suitable for current consumers and the international market is still open to a great deal of debate and research. As a result, new claims within the classification system have been highlighted by Wilson (2015):

- The system classifies carcasses for the producer within the value chain, and is implemented efficiently at abattoirs, but when the same product that has been classified in different price groups is displayed at some retail points, it is labelled only as beef, mutton or lamb. The meat is sold at a single price with no quality options indicated by classes.

- The red meat value chain is not completely transparent and the message between the producer and consumer is not communicated effectively within the value chain.

The major concern about the current classification system is whether it is still relevant in terms of consumer needs and international criteria (RMIF, 2016). Based on these claims, one might argue that the system and its purpose seem to be supply driven instead of consumer driven. Likewise, it is still unclear whether consumers buy meat according to the standards set by the system. This is crucial, and research should be conducted to evaluate consumer knowledge of the red meat classification system, and its effect on consumer choices. The guarantee of meat quality under the South African classification system must also be taken into account when conducting such a study.

The purpose of a quality system is not only to evaluate meat quality, but also to analyse critical points of production that could influence the final quality of meat. For instance, approximately $80 \%$ of cattle marketed in South Africa originate from feedlots, and are therefore from the A age group and to some extent $A B$ age group with fat codes 2 and 3 . These are ideal classes, which are preferred by the market, and thus end up in retail. This means that most of the meat offered to the consumer comes from young animals with low fat content and normally could be of good quality. The remaining $20 \%$, which does not meet the maximum requirements of the classification system (probably $B$ and $C$ classes from grass-fed animals), is channelled to alternative markets such as the processing sector. In this way, the system presumes that consumers have similar meat preferences, and thus does not promote consumer confidence with regard to the origin of meat and the product content, so that consumers could make their meat choices according to their preferences.

In this regard, the current meat classification should be kept as a basic price-forming mechanism, but parallel and additional quality systems should be allowed and encouraged. Retailers and abattoirs for example may decide to market meat from a specific production system (grainfed or grass-fed), free of growth stimulants, with consistently more tender muscle as a result of electrical stimulation and a maturation protocol.

\section{Implications of the red meat classification system for current consumer meat preferences}

Like the (S)EUROP classification system in Europe, the South African red meat classification system is merely one of the schemes that are used to determine the value of the carcass without indicating the quality of meat. Such a system describes only quality related to the characteristics of carcasses (Soji et al., 2015a), but not cuts or muscles. As a result it is of limited value to consumers (Guzek et al., 2016). Figure 1 below shows the South African red meat classification scale based on fat cover and age. 


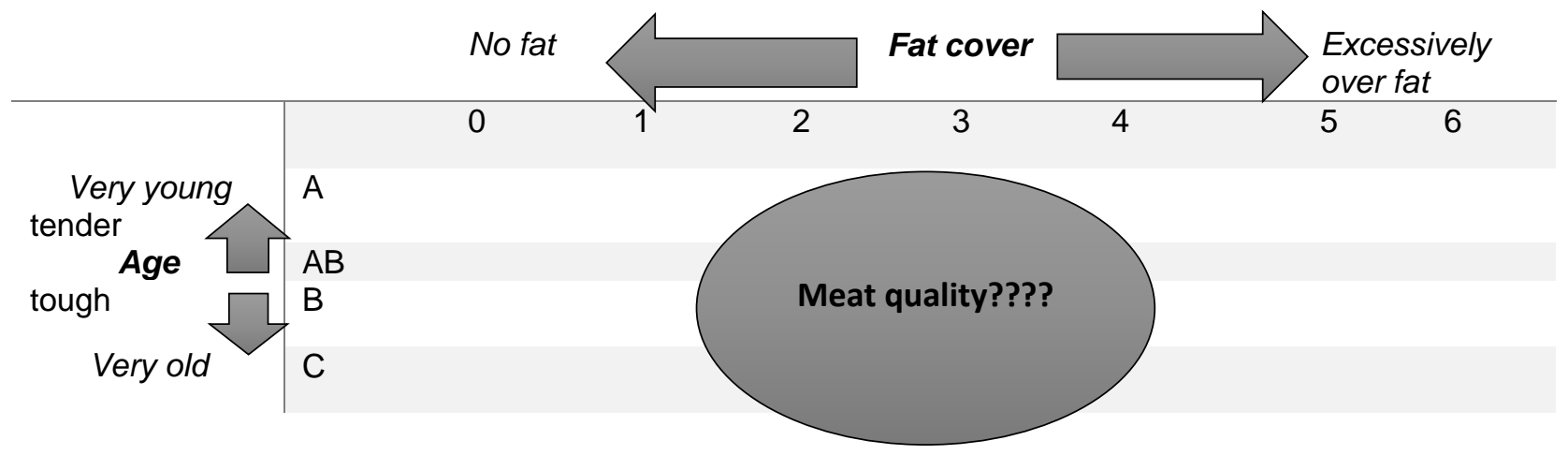

Figure 1 South African red meat classification based on age and fat cover

According to Spies (2011), price per kilogram of a carcass in the South African classification system varies from class to class, with a substantial fall from $A 2$ and $A 3$, which are consumer ideal classes. Wilson (2015) indicated that any deviation from these ideal classes results in price reduction, ranging between $15 \%$ and $20 \%$. However, meat quality in these classes is unaccounted for, and this has implications for the current consumer. For instance, in a study by Guzek et al. (2016) in Poland, consumer preferences for grilled steaks were not influenced by fat class, conformation, fat thickness, and ossification scores, but by the types of meat cuts. Similarly, in a study by Bonny et al. (2016), it was highlighted that while the European carcass classification system may indicate yield, it has no consistent relationship with sensory scores at carcass level that is suitable for use in the commercial system. These are the same challenges that beset South African consumers.

Classification and grading systems vary, depending on their objectives. For instance, the United States, Canada, Japan, South Korea, and Meat Standards Australia (MSA) use grading systems based on marbling, age, and sex of slaughter animals (Polkinghorne \& Thompson, 2008). South Africa, Europe, Namibia and Australia (AUS-MEAT) on the other hand use a classification system based on external fat covering, conformation, and age of the animal. Some systems, such as MSA, also measure meat eating quality attributes such as $\mathrm{pH}$, lean and fat content, firmness and texture (Polkinghorne \& Thompson, 2008). However, such attributes are not included in classification systems such as the South African one.

Based on the criteria used in these systems, it is clear that the South African system does not classify meat based on eating quality. A review by Soji et al. (2015b) confirmed this. The authors commented that the system is strongly inclined towards meat sellers, and does not attempt to indicate the expected eating quality of the carcasses. The South African red meat industry, however, still emphasizes that the classification system involves carcass description and not quality assurance (RMIF, 2016). It is similar to the system used by the United States (USDA), Europe and the conventional Australian system. On one hand, the industry emphasizes that the voluntary MSA is one of the few systems that describe quality, but remains too expensive to be implemented in South Africa. On the other hand, the demand for red meat is gradually declining in industrial countries such as South Africa (Bureau of Food and Agricultural Policy (BFAP), 2013).

Health risks associated with the consumption of red meat and red meat products, such as high total and saturated fat content, along with product quality issues, are well-documented contributing factors to this phenomenon (Hall et al., 2015). As a result, more consumers around the world are willing to change their standards of living to reduce the risk associated with unhealthy food choices (Peng, 2004), including meat. Such lifestyle changes may influence consumer willingness to buy high-quality grades and classes, even in South Africa. For instance, research into consumer willingness to pay for eating quality showed that Australian consumers are prepared to pay higher prices for better eating quality grades (Polkinghorne \& Thompson, 2010). Thus, even if the implementation of the quality-based system is expensive and requires sophisticated technologies, consumers might still pay increased prices if they were assured of high quality. Therefore, the acquisition of knowledge about consumer willingness to pay higher prices for high quality classes in South Africa needs to be implemented. In that way, the industry would be able to make an informed decision on developing a classification system that would measure both carcass yield and meat eating quality. Such a system could reinforce the advancement and application of a transparent value chain. 


\section{Inadequacy of quality-based information in the current classification system and possible solutions}

In some countries animal carcasses are classified and graded based on quality (above). So carcasses with superior quality receive higher premiums in markets than those of inferior quality. In such countries, producers are inclined to supply carcasses that produce meat of superior quality. Consumers are assured of high quality through meat labelling and thus pay higher prices for premium meat than for inferior quality meat. It is mostly acknowledged that the current South African classification system is not a grading system, and so its intention is not to supply labelling information. However, additional information, such as production system, electrical stimulation system and ageing, could be supplied through labelling. Such information could indirectly provide knowledge to consumers about the expected eating quality from different classes. Schönfeldt \& Hall (2015) also suggested that new labelling regulations should be implemented to market unique red meat and red meat products to consumers. The authors added that labelling fresh red meat as sources of certain beneficial nutrients and emphasizing product qualities such as low fat and sodium-based nutrients could encourage consumers, at the point of purchase, to buy more red meat. Webb (2015) concurs, highlighting that many researchers have recommended that labelling and branding meat products would provide a coherent alternative to guarantee preferred quality. In that way the current classification system would not necessarily be changed into a grading system, but into a system that is closely linked to consumers' most appreciated quality attributes. This should be done to ascertain the legitimacy of the system for marketable red meat products and as a way of inhibiting red meat from losing its market niche, since red meat consumption is currently reported to be gradually declining.

Aside from price differences between white and red meat, the inadequacy of quality-related information in the current system has resulted in South African consumers preferring white meat to red meat (BFAP, 2011). Although white meat does not show quality options at retail points either, it is often associated with fewer health risks than red meat. There is therefore a need to evaluate the composition and nutritional profile of beef carcasses over the four age-group classes in beef (Hall et al., 2016), and the PORCUS classes in pork. By doing so, updated scientific data would be available for the nutritional composition of fresh red meat that is labelled in different carcass classes. This would be beneficial to consumers and the market for satisfaction and transparency, respectively.

\section{Are the South African classification characteristics efficient for a quality-based system?}

An evaluation of the current red meat classification system has shown that there are approximately 120 combinations of age and fat classes by which South African carcasses can be classified (Webb, 2015). The author highlighted recent data from the Red Meat Abattoir Association, which indicated that only 5-10\% of these combinations are used efficiently, notable classes being $A 2, A 3, A B 2$, and $A B 3$, while small proportions are classified in other categories. This distribution can be associated with market specifications, because the South African system values animals of younger and leaner carcasses highly, which consequently fetch high premiums and are thus mostly demanded in the market. The emphasis on lean meat content and the notion that excess fat is discarded are undoubtedly the main reasons for the notable shift towards the production of carcasses with very specific fat codes ranging between 2 and 3 (Webb, 2015).

On the other hand, age is known to affect meat tenderness, which explains why it is also one of the price-determining factors of the current system. However, there is still no strong clear relationship between meat quality and South African fat and age scores (Soji \& Muchenje, 2016). If the value of the carcass is to be determined by a combination of quality and yield, then the system should look beyond age and fat scores. For instance, tenderness is regarded as the most difficult attribute to predict (Koohmarie, 2002). Thus, it arouses a strong belief that a classification system would never be able to predict tenderness beyond the point of age classification. But many other factors contribute to tenderness. The concept is complex and dependent on a combination of physiological factors (Ouali, 1990). Factors such as breed (Soji \& Muchenje, 2016) and production system (Frylinck et al., 2015) influence tenderness. In a study by Frylinck et al. (2015), it was discovered that animals with 3-6 permanent incisors at slaughter do not necessarily produce tougher meat than those of 0-2 incisors. Also some breeds, such as Nguni, produce tender meat up to an older age on both pasture and feedlot systems. Although it is generally expected that meat from pasture animals would be tougher than feedlot animals, it was shown in the study that meat from pasture animals became tender at the older B-age class (Frylinck et al., 2015).

Likewise, factors such as marbling and fat quality, which are also interrelated with production system and age, affect tenderness. Thus, many factors, besides age, may contribute to variety in tenderness in the same carcass classes. This concurs with reports by Frylinck et al. (2015), Modika et al. (2015), and Soji \& Muchenje (2016) that age alone might not be an adequate classification trait for tenderness. Consequently, if the value of the carcass were to be determined by a combination of quality and yield, then the South African classification system should look beyond age and consider such factors when classifying for tenderness. 
Additionally, the fat class should not be based only on the amount of subcutaneous fat, but on other quality parameters such as fat colour and fatty acid composition, especially since meat from different production systems has varying quality attributes including fat colour, which is highly associated with the fatty acid profile. This would provide a quality-based system that would be transparent at all levels in the value chain. The South African classification system therefore needs to be re-evaluated to assess its validity in terms of tenderness and fat quality in relation to the quality preferences of the current consumer, since these factors are key price determining factors in the system.

\section{Tenderness and fat content evaluation in the current system in relation to consumer demands}

The current system uses age as the sole indicator of tenderness, implying that optimum tender meat is obtained from younger animals with no permanent incisors (A class). However, Strydom (2011) argued that recent studies confirm that if modern technologies are taken into consideration, this is not fundamentally true. Furthermore, Webb \& Erasmus (2013) indicated that there are significant variations in carcass composition and quality owing to the effects of age, species, sex, maturity type, and interaction with production systems and technologies. This suggests that the current system might sometimes disadvantage farmers who produce animals with up to four permanent incisors, and who might produce meat with similar or even better tenderness than the current A class (Moloto et al., 2015; Soji \& Muchenje, 2016). Although meat tenderness is predicted on age alone in the current South African system, Webb (2015) indicated that meat tenderness could be measured objectively (with instruments) and subjectively (using sensory evaluation). Nonetheless, there is no technique that is used in the current system to predict meat tenderness of a carcass precisely at abattoir level to classify tenderness according to eating quality. Meat tenderness is highly variable and is affected by the meat cut and a range of intrinsic and extrinsic factors associated with the conversion of muscle to meat (Kemp \& Parr, 2012; García-Marcia et al., 2014; Guzek et al., 2016). Zhao et al. (2014) stated that beef tenderness is a complex trait that can further be dictated by the four structural elements of the muscle (muscle fibres, sarcomere length, connective tissue, and intramuscular fat)

Swatland (2003) highlighted the challenge to improve tenderness through genetics if nanostructure components, such as sarcomere length, muscle fibre orientation, and fibre texture, are not known. This is mainly because the structure of the muscle and the size of the fibres affect the connective tissue and tenderness of meat (Chulayo \& Muchenje, 2016). These authors added that the chemical composition and biological properties of these muscles are important for better knowledge of major causes of the variations in meat quality, mainly colour, intramuscular fat, and tenderness. Additionally, irrespective of carcass class, genotype is identified as one of the factors that contribute as a source of variation in beef tenderness. Although studies have provided evidence that electrical stimulation reduces the variability in tenderness of different genotypes (Ferguson et al., 2000; Frylinck, 2001), Soji \& Muchenje (2016) still found significant differences in tenderness of carcasses from different beef genotypes subjected to similar post-slaughter treatments, including electrical stimulation. Chulayo \& Muchenje (2016) also indicated that some beef muscles received less attention from consumers owing to reduced tenderness. Therefore, other factors, which include breed or genotype, may be considered when classifying tenderness.

Furthermore, Dransfield (1995) suggested that marbling and fat profile account for about $10 \%$ of variation in longissimus tenderness. Frylinck et al. (2015) concurred that intramuscular fat (marbling) plays an important role in the tenderness of beef. Although marbling is known to affect tenderness, it is not evaluated in the current South African classification. Thus, little is known about how marbling could induce sources of variation in tenderness within and across carcass classes. In addition, much attention has been paid to the fat content of carcases with certain fat codes (2-3) being the most marketable. Nonetheless, less or no attention has been paid to the effects of fat quality on tenderness, precisely intramuscular fat quality. Fat quality is known to play a vital role in meat and meat products (Hugo \& Roodt, 2015). Fat quality components, such as increased amounts of unsaturated fatty acids, may result in a lack of cohesiveness between muscle and adipose tissue on cutting (Hugo \& Roodt, 2007) and this might influence meat tenderness. Besides, most research has focused on the fatty acid profile of beef without considering the relationship between tenderness and fat quality, particularly from different production systems. Such information is still lacking and not considered in the South African classification system.

The South African classification system sets the standards for the entire red meat value chain, which includes the producers, abattoirs, wholesalers, retailers, retail butchers and, most importantly, the consumer. Consumer behaviour forms the heart of the value chain. Hence, it is important for the classification system to satisfy the expectations of the consumers of meat tenderness, since it is the most appreciated quality attribute. Luciano et al. (2007) indicated that it is a real challenge for the scientific community and the meat industry to achieve products with standardized and guaranteed tenderness. This is the worst case scenario for the South African classification system since it depends only on age as an indicator of meat tenderness. 
As a result, there are enormous concerns about the inconsistent meat tenderness from South African beef. The South African meat industry should therefore identify measures to solve the problem of inconsistent meat tenderness as a top priority. This requires a detailed understanding of the processes affecting meat tenderness and, most importantly, the utilization of such information by the South African beef classification system. Although some of the techniques proposed for amending the classification system, particularly in terms of tenderness, might not be feasible at abattoir level and have cost implications, through further research and persistence they could be simplified and technologies that are user friendly could be developed for use in the current South African classification system.

\section{Current research on the South African red meat classification system}

A study that evaluated the relationship between carcass characteristics and back-fat quality of South African pigs was conducted by Hugo \& Roodt (2015). The study showed significant differences in back fat quality of the various pig classification groups (PORCUS). Schönfeldt \& Hall (2015) also conducted a study on the nutrient content of South African red meat and the effects of age and production system. In this study, differences were observed between animals of different age groups and production systems in terms of fat content and quality, in which animals from pasture-based systems contained more n-3 fatty acids and linoleic acid per edible portion than the feedlot animals. A study by Hall et al. (2015) presented the compositional data of South African lamb, mutton, and beef, and changes observed between local and international data (for lamb and mutton). In the study, significant changes in the composition of red meat were identified, particularly in fat content. The authors suggested that continued research on composition needed to be done for the baseline information to remain relevant and accurate. Additionally, a study by Hall et al. (2016) indicated that when South African beef is trimmed of visible fat, it compares favourably in terms of lipid content with other lean animal sources of foods such as chicken without skin and trimmed mutton and pork. The authors stated that this applies to both older and younger animals, which may be reduced up to $10 \%$ and $3.5 \%$ lipid, respectively.

Furthermore, approaches to evaluate meat tenderness have been studied that include visual evaluation of beef tenderness using surface structural observations and its relationship with meat colour (Modika et al., 2015); the beef tenderness model by Frylinck et al. (2015); and the proteomics approach as a new way to predict tenderness compared with the classical South African beef carcass classification system (Moloto et al., 2015). All these studies give overviews of possible procedures that could be used to achieve consistent tenderness in the South African classification system, and signal a need to revise the system in terms of tenderness.

Additionally, a study by Strydom et al. (2015) evaluated sources of variation in the quality of South African beef. In the study, it was indicated that $A B$ class animals from different feeding regimes have different meat quality attributes with regard to taste. In addition, a study by Soji et al. (2015a) evaluated the associations between animal traits, carcass traits, and carcass classification. The study suggested that animal traits, such as breed, and carcass traits, including warm carcass mass, have an effect on carcass classes. Subsequently, a study was conducted to evaluate the effect of genotype and age on some carcass and meat quality traits of beef subjected to the South African classification system (Soji \& Muchenje, 2016). The study showed that although carcasses might be categorised into one class, differences in the number of incisors at slaughter and genotype induce variation in meat quality attributes within the same class.

Many factors (intrinsic and extrinsic) contribute to meat quality and these are not effectively described in the current South African classification system. These factors contribute significantly to the variation in carcass and meat quality of red meat, despite categorization into similar classification groups. It is therefore strongly suggested that the South African red meat classification system should not depend or make decisions based on only a few research studies. Most of these studies were all conducted on red meats (beef, mutton, and lamb), with the exception being goat meat. Goat meat forms part of the South African red meat classification system and therefore needs to be evaluated as much as other red meat species.

\section{Current state in the marketing of goat meat through the South African red meat classification system}

Goats play an indispensable role in the subsistence of many communal farmers in many developing nations (Musara et al., 2013), including South Africa. The goat enterprise is widely known for its low input requirements and as an easy entry and easy exit project, due to its affordable built-in costs. Furthermore, among its nutritional benefits, goat meat (chevon) is lower not only in total fat and cholesterol, but also lower in saturated fats than other red meats (Correa, 2008). In South Africa, goats are mostly slaughtered during cultural ceremonies and informally. In other words, they are slaughtered in a specific way for distinctive ceremonies and its meat is specific to certain individuals according to the ritual of the families. They are sometimes slaughtered at abattoirs on request by the Muslim community. Thus, goat meat seems to be 
favoured or consumed by a few specific communities in South Africa, such as those from the communal areas, and has difficulty in competing for a considerable market share in the industry. It has received less attention in terms of marketing and, unfortunately, is dismissed because of the undesirable odour. Hence, goat producers are always inclined to sell through the informal market.

In spite of the roles of goats in the rural livelihood and economies of developing countries, their production is concealed by a number of factors, which give an underestimation of what this enterprise has to offer. Goats and the rural folk who keep them are therefore given low status and less attention in national developments (Simela, 2005). This is mainly because, although the current South African classification system classifies goat carcasses in the same manner as other red meat, chevon formal marketing has been ignored by many rural and small-scale farmers. As a result, it is even difficult to obtain goats and their products from the abattoir, since they seldom enter the formal market. This may be because rural farmers are not knowledgeable about formal marketing of goats and its benefits. Additionally, historical legacies and structures, insufficient research on goat meat and technological development in Africa constrain goat meat marketing (Musara et al., 2013). Thus, in spite of certain beneficial carcass traits, such as lower fat percentage compared with other red meats, as well as favourable meat to bone ratio per capita, chevon consumption in South Africa is low compared with other red meat types (DAFF, 2012). As a result, it becomes difficult to find a market niche for goats in the formal market, since it is not considered a good enterprise owing to low supply.

However, besides its lower acceptability by most consumers and sometimes the industry, goat meat is more nutritious and contains fewer allergens than other red meat (Correa, 2008). Therefore, more research should be implemented to create an appreciation of the benefits of consuming chevon both to farmers and consumers. This may help in creating a market niche for chevon in the South African meat industry. Such research might provide information and knowledge to goat farmers about formal marketing and how this could contribute to food security. Thus, goat producers, researchers, and other interested parties should be invited to provide data to assist in the development and promotion of appreciating the relevance of chevon formal marketing through the South African classification system, to communal farmers in particular. Therefore, before trying to develop research that might help in amending the classification system, it is important to note that species such as goats are less marketed through the formal classification system and to determine whether other classification traits are still relevant for all meat species as this may provide a comprehensive classification system.

\section{Are other traits in the classification system still relevant? \\ Conformation classification}

Apart from the classification traits of age and fat cover the South African carcass classification system considers sex, bruising, and conformation (SAMIC, 2006). This is designed to guarantee the consumer and the meat trade that meat of their choice should reach them. Among the current classification characteristics, carcass conformation is invariably used as a general indicator of the quality of the carcass, which involves a visual assessment and objective measurements, such as the width and depth of the thorax, length of legs, and width of the rump or the area of the rib eye (Frylinck et al., 2013). Nonetheless, there are queries about the importance of conformation as an indicator of carcass composition. This has triggered disputes and generated research efforts in sheep and beef cattle (Hope-Jones et al., 2010). This is mainly because there is still uncertainty about the emphasis that should be placed on conformation class in sheep carcasses. It was highlighted at a carcass classification workshop conducted by RMRD SA that the evaluation of body conformation might be well recognized and more significant for beef carcasses than mutton carcasses (RMIF, 2016). Nonetheless, Hope-Jones (2010) indicated that conformation has much to do with determining the relative appeal of the carcass. It has therefore since been argued that the main significance of conformation is the indication of the ratio between meat and bone, as well as the ratio between the most desirable cuts, such as rounds and loins, and coarser cuts such as chuck and plate. Strydom (2011) highlighted that carcass conformation has traditionally been used by meat traders as an indicator of carcass quality. The author, added that conformation covers the general build, form, shape, contour and outline of the carcass side or cut. Researchers have therefore tended to view conformation as an unimportant characteristic. Although conformation has long been reported not to directly affect meat quality, it has long been indicated to affect consumer purchasing decisions on preferred cuts (SAMIC, 2006). Therefore, there is a need to investigate whether a different system should be developed for sheep conformation classification or whether it should not be included in the South African classification system at all, since it is assumed not to be related to meat quality or perhaps should be used only as a characteristic to indicate consumer cut preferences. This can be done by evaluating the effect of conformation on consumer choices, and on carcass and meat quality characteristics of beef and mutton. 


\section{Bruising classification}

It is mostly acknowledged that the event of bruising negatively affects animal welfare and has an effect on meat quality (Strappini et al., 2009; Mpakama et al., 2014). Bruising is defined as discoloration and bleeding at the site of an injury, and can seriously reduce the value of a carcass. Although a classification trait such as bruising is part of the classification system in the form of damage class, the extent to which bruising may have an effect on meat quality is not quantified in the system. Bruises on carcasses are normally trimmed off during primary meat inspection just after evisceration. Bruised meat decomposes and spoils more rapidly because bloody areas stimulate bacterial growth when not removed (Hoffman et al., 2010). Consequently, the effects of bruising can be seen on dark coloured meat (DFD), toughness, reduction of meat shelf life, poor palatability, and reduced water-holding capacity (Muchenje et al., 2009; Vimiso \& Muchenje, 2013). Although it may seem impossible to quantify the effects of bruising based on these qualityrelated problems, the time at which trimming of bruises is performed at the abattoir may help reduce them without using sophisticated measurements that would complicate the system.

In the current classification system, the trimming process takes place at approximately \pm 45 minutes post mortem in warm carcasses. Nonetheless, in an ostrich study by Hoffman et al. (2010) it was found that trimming bruises on warm carcasses results in higher total aerobic viable counts on the trimmed surface than cold trimming, which consequently results in quality-related problems (above). This is mainly because the muscle area is often exposed during trimming. Thus, the meat becomes more susceptible to aerobic bacterial contamination (Hoffman et al., 2010). The authors stressed that in any abattoir, sources of bacterial contamination are present along the slaughter line, in the chilling rooms, and the deboning areas. Microorganisms in these areas can cross-contaminate the trimmed areas of a carcass. Thus, cold trimming has a better chance of reducing most quality-related problems associated with bruising, since it is approximately the last stage during abattoir processes and the trimmed areas would have not been much exposed to aerobic contamination. If such trimming management practices could be applied in the current red meat classification system, consumers would not need to worry about the extent to which bruising may have affected meat in terms of quality and safety. Subsequently, the system would have guaranteed safe and good quality meat. A study that would measure the effects of trimming stage on bruised carcasses of red meat therefore needs to be done.

\section{Possible combination of $A$ and $A B$ age carcass classes}

Dissimilarity in eating quality, mainly tenderness, is the main concern of consumers with perceived toughness resulting in unacceptable eating quality. In the formal market, animals are slaughtered mostly at a young age (A class) before the outbreak of permanent incisors (Government Gazette R.342 of 1999) or after development of up to two permanent incisors ( $A B$ class). However, there is an unending argument that $A$ and $A B$ beef classes are the same in terms of meat quality (tenderness, juiciness, firmness, and flavour), and should therefore be combined. This was highlighted at the RMRD SA carcass classification workshop. However, a question of concern would be under which circumstances should these classes be combined, because the South African beef classification system does not measure the quality of meat. According to the SAMIC (2006), based on age of the animal, class A (0 incisors) is mostly tender, while class AB (1-2 incisors) has reduced tenderness; thus, the conclusion that tenderness decreases with age. This difference in tenderness, however, is estimated based on a visually appraised dentition method without necessarily measuring tenderness with technical methods such as Warner Bratzler shear force and other techniques. However, Soji \& Muchenje (2016) argued that the number of incisors at slaughter has an effect on the meat quality of carcasses in the same class particularly meat tenderness. This could be the worst case scenario between $A$ ( 0 incisors) and $A B$ (1-2 incisors) classes. Furthermore, in a study by Frylinck et al. (2009) it was observed that loin steaks of feedlot carcasses with $A$ or $A B$ classes were mostly more tender than those of pasture carcasses with $A, A B$ and $B$. Thus, if these classes were to be combined, would the combination cater for different production systems? For such decisions to be made, research should be conducted on similarities and differences in meat quality attributes from $A$ and $A B$ animals. Such research should also consider the production system.

\section{Effects of different production systems on the classification system}

A review by Soji et al. (2015b) investigated the relevance of the current classification to the informal sector. The study indicated that the informal sector comprises mostly communal farmers, who perceive their profitability as being negatively affected by the formal classification system. Among the challenges highlighted, the downgrading of their carcasses because of yellow fat colour is major. Cattle finished on pastures mostly have yellow fat owing to high carotene levels, while grainfed animals have white fat. It is speculated that the current classification system favours white fat carcasses from feedlot farmers. However, it is important to note that not all consumers prefer white fat carcasses. For instance, in a study by 
Thompson et al. (2010) it was highlighted that some consumers preferred meat produced from the natural pasture-raised cattle. For this reason, it is of paramount significance to create a market that will cater for these consumers in a well-structured way.

Furthermore, indigenous breeds such as Nguni from communal farmers are often overlooked in the formal markets as they are perceived to be inferior owing to slow growth rates, which consequently result in low carcass weights (Muchenje et al., 2008). Chingala et al. (2017) also indicated that the current beef carcass and grading systems used in the Southern Africa region inappropriately value indigenous cattle. For this reason, most communal beef farmers are reluctant to sell their cattle through the formal market. This could be because the system seems to cater only for young and well-muscled cattle. Since the communal farmers keep their cattle for longer to perform other purposes, Marandure et al. (2016) recommended that the South African carcass classification system should be revised to consider older animals. Chingala et al. (2017) also suggested the use of biotechnology and machine-based technology for prediction of carcass yield and quality as well for obtaining additional value for carcasses from cattle finished off natural pastures. The authors further highlighted an opportunity to establish credible quality attribute-based markets that will take advantage of indigenous breeds' adaptability and the benefits of meat from animals reared on natural pasture based production systems. These factors also give rise to other issues that need to be addressed through the red meat classification system. Such issues include:

- The inclusion of breed in the classification system

- The inclusion of production system

- The inclusion of fat colour

- The inclusion of intramuscular fat

- Other means of measuring tenderness other than age of the animal

In turn, these will need to be communicated to consumers through labelling (above), branding, and consumer awareness systems. Thus, a key to a more effective way of red meat marketing in South Africa would be to provide a quality-based classification system from which consumer needs would be satisfied.

\section{Conclusion}

Although the South African red meat industry emphasizes that the current red meat classification system is still relevant, many factors that affect consumers have not been catered for. For instance, there are concerns about the quality of meat that consumers buy and its origin. Although it is a good classification, the current system does not meet all the needs and requirements of the consumer. As a result, many questions about the system remain unanswered. More research should be done to make a conclusive decision on whether the classification system should be maintained, amended, or completely changed. Alternative measures must be investigated to enable the inclusion of meat quality in the South African red meat classification system and the subsequent provision of a quality product to the consumer. Technologies to measure tenderness and intramuscular fat at abattoir level during carcass classification need to be developed. Similarly, classification according to breed and production systems may need to be incorporated in the system.

\section{Acknowledgements}

This work is based on research supported by the Meat Industry Trust (MIT) Authorization number IT8114/98 and the National Research foundation (NRF), Grant number 101171-2016. The views expressed in this article are those of the authors, and not the sponsors.

\section{Authors' contributions}

Conception, design, critical revision and final approval of version to be published was done by both ZS and VM.

\section{Conflicts of Interest Declaration}

The authors certify that there are no conflicts of interest.

\section{References}

BFAP, 2011. Bureau for Food and Agricultural Policy: The South African agricultural baseline. Available at www.bfap.co.za. Accessed 19 October 2016.

BFAP, 2013. Bureau for Food and Agricultural Policy, Baseline. Available at www.bfap.co.za/documents/baselines/BFAP_Baseline_2013.pdf. Accessed 19 October 2016.

Bonny, S.P.F., Pethick, D.W., Legrand, I., Wierzbicki, J., Allen, P., Farmer, L.J., Polkinghorne, R.J., Hocquette, J.F. \& Gardner, G.E., 2016. European conformation and fat scores have no relationship with eating quality. Animal. 10, 996-1006.

Chingala, G., Raffrenato, E., Dzama, K., Hoffman, L. C. \& Mapiye, C., 2017. Towards a regional beef carcass classification system for Southern Africa. S. Afr. J. Anim. Sci. 47, 408-423. 
Chulayo, A.Y. \& Muchenje, V., 2015. A balanced perspective on animal welfare for improved meat and meat products. S. Afr. J. Anim. Sci. 45, 452-469.

Chulayo, A.Y. \& Muchenje, V., 2016. Effects of animal class and genotype on beef muscle nanostructure, pHu, colour and tenderness. S. Afr. J. Sci. 112, 7-8.

Correa, J.E., 2008. Nutritive value of goat meat. Alabama Cooperative Extension System, UNP.

Available

at http://www.aces.edu/pubs/docs/U/UNP-0061/UNP-0061.pdf. Accessed 19 October 2016.

Dransfield, E., 1995. Control of meat texture at an industrial scale. Expression of tissue proteinases and regulation of protein degradation as related to meat quality. Edited by A. Ouali, D. J. Demeyer, \& F.J.M. Smulders, ECCEAMST. pp 463-482.

DAFF, 2012. A profile of the South African mutton market value chain. Available at www.nda.agric.za/docs/AMCP/Mutton13.pdf. Accessed 20 March 2016.

Ferguson, D.M., Jiang, S.T., Hearnshaw, H., Rymill, S.R. \& Thompson, J.M., 2000. Effect of electrical stimulation on protease activity and tenderness of M. longissimus from cattle with different proportions of Bos indicus content. Meat Sci. 55, 265-272.

Ford, L., Matthews, K., Hadley, P., Homer, D. \& Drewett, M., 2012. A glossary of carcass and meat quality terms. Available at http://beefandlamb.ahdb.org.uk/. Accessed 19 October 2016.

Frylinck, L., 2001. Guaranteeing meat tenderness - a research priority for South Africa. Meat Industry Summit 2001. Holiday Inn, Johannesburg International Airport.

Frylinck, L., Strydom, P.E., Webb, E.C. \& Du Toit, E., 2013. Effect of South African beef production systems on postmortem muscle energy status and meat quality. Meat Sci. 93, 827-837.

Frylinck, L., O’Neil, A., Du Toit, E., Strydom, P.E. \& Webb, E.C., 2015. The beef tenderness model. S. Afr. J. Anim. Sci.45, 235-248.

García-Marcia, M., Siera, V., Palanca, A., Vega-Naredo, I., de Gonzalo-Calvo, D., Rodríguez-Gonzáilez, S., Oliván, M. \& Coto-Montes, A., 2014. Autophagy during beef aging. Autophagy 10, 137-143.

Grandin, T., 2007. Stress physiology of animals during transport In: Livestock handling and transportation, 3rd Ed. CABI, New York, pp.318-319.

Guzek, D., Glabska, D., Gutkowska, K. \& Wierzbicka, A., 2016. Effect of carcass fat and conformation class on consumer perception of various grilled beef muscles. J. Food Sci. Technol. 53, 3778-3786.

Hall, N., Schönfeldt, H.C. \& Pretorius, B., 2015. Changes in the composition of South African red meat. S. Afr. J. Anim. Sci. $45,325-338$.

Hall, N., Schönfeldt, H. \& Pretorius, B., 2016. Effect of animal age and trimming practices on the physical composition of Bonsmara beef. Food Chem. 193, 160-165.

Hoffman,L.C., Britz, T.J. \& Schnetler, D.C., 2010. Bruising on ostrich carcasses and the implications on the microbiology and losses in utilizable meat when removing them post-evisceration or post chilling. Meat Sci. 86, 398-404.

Hope-Jones, M., Strydom, P.E., Frylinck, L. \& Webb, E.C., 2010. The efficiency of electrical stimulation to counteract the negative effects of $\beta$-agonists on meat tenderness of feedlot cattle. Meat Sci. 86, 699-705.

Hugo, A. \& Roodt, E., 2007. Significance of porcine fat quality in meat technology. Food Rev. Int. 23,175-198.

Hugo, A. \& Roodt, E., 2015. Fat quality of South African pigs with different carcass classification characteristics. S. Afr. J. Anim. Sci. 45, 302-312.

Kemp, C.M. \& Parr, T., 2012. Advances in apoptotic mediated proteolysis in meat tenderization. Meat Sci. 92, 252-259.

Koohmaraie, M., Kent, M.P., Shackelford, S.D., Veiseth, E. \& Wheeler, T.L., 2002. Meat tenderness and muscle growth: is there any relationship? Meat Sci. 62, 345-352.

KwaZulu-Natal Department of Agriculture and Environmental Affairs (KZN DAEA), 2005. The beef carcass classification system. Available at www.kzndard.gov.za Accessed 19 October 2016.

Luciano, F.B., Anton, A.A. \& Rosa, C.F., 2007. Biochemical aspects of meat tenderness: A brief review. Archivos de Zootecnea, 56: 1-8.

Marandure, T., Mapiye, C. \& Muchenje, V., 2016. Determinants and opportunities for commercial marketing of beef cattle raised on communally owned natural pastures in South Africa. Afr. J. Range Forage Sci. 33, 199-206.

Modika, K.Y., Frylinck, L., Moloto, K.W. \& Strydom, P.E., 2015. Visual evaluation of beef tenderness by using surface structural observations and its relationship to meat colour. S. Afr. J. Anim. Sci. 45. 255-262.

Moloto, K.W., Frylinck, L., Strydom, P.E. \& Koorsen, G., 2015. Proteomics approach as a new way to predict tenderness as compared to the classical South African Beef Carcass Classification System. S. Afr. J. Anim. Sci. 45, $249-254$.

Mpakama, T., Chulayo, A.Y. \& Muchenje, V., 2014. Bruising in slaughter cattle and its relationship with creatine kinase levels and beef quality as affected by animal related factors. Asian Austral. J. Anim. Sci. 27, 717-725.

Muchenje, V., Dzama, K., Chimonyo, M. \& Strydom, P.E., 2009. Relationship between pre-slaughter responsiveness and beef quality in three cattle breeds. Meat Sci. 81, 653-657.

Muchenje, V., Dzama, K., Chimonyo, M., Raats, J.G. \& Strydom, P.E., 2008. Meat quality of Nguni, Bonsmara and Angus steers raised on natural pasture in the Eastern Cape, South Africa. Meat Sci. 79, 20-28.

Musara, J.P., Chimvuramahwe, J., Munyati, V., Chivheya, R \& Mwadzingeni, L., 2013. Why not commercial goat production? Exploring rural communities' preference for livestock enterprises. Case of Matsai communal area, Zimbabwe. J. Agric. Res. Dev. 3, 026-034.

National Agricultural Marketing Council (NAMC), 2001. Report on the investigation into the effect of deregulation on the red meat industry. Available at www.namc.co.za. Accessed 03 May 2017.

Ouali, A., 1990. Meat tenderization: Possible cause and mechanisms. 1990. A review: J Muscle Foods, 1, 129-165.

Peng, Y., 2004. Canadian consumer trends in obesity and food consumption. Economics \& competitiveness. Consumer food trends reports. Strategic Information Services Unit (780):427-4248. Yanning.peng@gov.ab.ca 
Polkinghorne, R. \& Thompson, J.M., 2010. Meat standards and grading. A world review. Meat Sci. 86, $227-235$.

Polkinghorne, R., Thompson, J.M. Watson, R., Gee, A \& Poter, M., 2008. Evolution of the Meat Standards Australia (MSA) beef grading system. Aus. J. Exp. Agric. 48, 1351-1359.

RMIF, 2016. Beef and lamb/mutton meat carcass classification system. Available at www.redmeatsa.co.za. Accessed 19 October 2016.

SAMIC, 2006. Available at www.samic.co.za. Accessed 19 October 2016.

Schönfeldt, H.C. \& Hall, N., 2015. Nutrient content of South African red meat and the effect of age and production system. S. Afr. J. Anim. Sci. 45, 313-324.

Simela, L., 2005. Meat characteristics and acceptability of chevon from South African indigenous goats. PhD thesis, University of Pretoria, South Africa.

Soji, Z. \& Muchenje, V., 2016. Effect of genotype and age on some carcass and meat quality traits of beef carcasses subjected to the South African classification system. Meat Sci. 117, 205-211.

Soji, Z., Mabusela, S.P. \& Muchenje, V., 2015a. Associations between animal traits and carcass classification in a selected abattoir in the Eastern Cape Province, South Africa. S. Afr. J. Anim. Sci. 45, 278-288.

Soji, Z., Chikwanda, D., Chikwanda, A.T., Jaja, I.F., Mushonga, B. \& Muchenje, V., 2015b. Relevance of the formal red meat classification system to the South African informal livestock sector. S. Afr. J. Anim. Sci. 45, 263-277.

Schönfeldt, H. C., 2015. Editorial, South African Journal of Animal Science. Special issue: Relevance of the South African carcass classification system. S. Afr. J. Anim. Sci. 45 (3), editorial.

Spies, D.C., 2011. Analysis and quantification of the South African red meat value chain. PhD thesis. University of Free State, Bloemfontein, South Africa.

Strappini, A.C., Metz, J.H.M., Gallo, C.B. \& Kemp, B., 2009. Origin and assessment of bruises in beef cattle at slaughter. Animal 3, 728-736.

Strydom, P.E., Frylinck, L., Van Heerden, S.M., Hope-Jones, M., Hugo, A., Webb, E.C., Moholisa, E., Liebenberg, B.E. \& Sehoole, O.C., 2015. Sources of variation in quality of South African beef: Case studies in relation to the red meat classification system. S. Afr. J. Anim. Sci. 45, 289-301.

Strydom, P.E., 2011. Quality related principles of the South African Beef classification system in relation to grading and classification systems of the world, S. Afr. J. Anim. Sci. 41, 177-193.

Swatland, H.J., 2003. Fibre-optic spectrophotometry of beef relative to sarcomere length. Archiv Tierzucht Dummerstorf. 46, 31-34.

Thompson, J., Polkinghorne, R., Gee, A., Motiang, D., Strydom, P., Mashau, M., Ngambi, J., De Kock R. \& Burrow, H., 2010. Beef palatability in the Republic of South Africa: Implications for niche-marketing strategies. ACIAR Technical Report 72 Canberra Australia: Australian Centre for International Agricultural Research. Available at https://www.cabdirect.org. Accessed 19 October 2016.

Vermeulen, H., Schönfeldt, H.C. \& Pretorius, B., 2015. A consumer perspective of the South African red meat classification system. S. Afr. J. Anim. Sci. 45, 239-353.

Vimiso, P. \& Muchenje, V., 2013. A survey on the effect of transport method on bruises, $\mathrm{pH}$ and colour of meat from cattle slaughtered at a South African commercial abattoir. S. Afr. J. Anim. Sci. 43, 105-111.

Warriss, P.D., 2000. Meat science: An introductory text. Tydskr. S. Afr. Vet. Ver. 71, 247-248.

Webb, E.C., 2015. Description of carcass classification goals and the current situation in South Africa. S. Afr. J. Anim. Sci. $45,229-233$.

Webb, E.C. \& Erasmus, L.J., 2013. The effect of production system and management practices on the quality of meat products from ruminant livestock. S. Afr. J. Anim. Sci. 43, 413-423.

$\mathrm{WHO}, 2016$. The nutrition source. Available at https://www.hsph.harvard.edu/nutritionsource/what-should-youeat/protein/. Accessed 26 December 2016.

Wilson, S., 2015. An exploratory study of consumer behaviour with the view to determine the effectiveness of the red meat classification system. MBA thesis. Stellenbosch University, South Africa. Available at http://scholar.sun.ac.za. Accessed 19 October 2016.

Zhao, C., Zan, L., Wang, Y., Updike, M.S., Liu, G., Bequette, B.J., Ransom, L., Baldwin, V.I. \& Song, J., 2014. Functional proteomic and interactome analysis of proteins associated with beef tenderness in Angus cattle. Livest. Sci. 161, 201-209. 